\section{A competition period evaluation in the long jump events in terms of seasonal Variables: Creating prediction models}

\section{Uzun atlama branşında bir yarışma periyodunun sezon değişkenleri yönüyle değerlendirilmesi: Performans tahmin modellerinin oluşturulması}

\author{
Berfin Serdil Örs ${ }^{1}$ \\ Işık Bayraktar ${ }^{2}$
}

\begin{abstract}
Aim: The purpose of training planning in performance sports is to achieve the desired performance in the target competition. Maintaining the desired performance in the major competition is the main subject of periodization. But at this point, the prediction of the season best, which will serve as a showcase for preparations, is a question as old as the history of training science for coaches. The aim of the study is to examine the variables in the competition period of female and male athletes participated in the top 100 places in the 2018 world lists in the long jump event, to compare by gender, and to create prediction models for the season best and season average performances (SPA) according to the average of first two performances (AF2P). Methods: Ages, total number of days in a season, the number of days between the competitions, total competitions, the number of competitions in which the season's best (SB) performance was achieved, the ratio of the $\mathrm{SB}$ to the total number
\end{abstract}

Özet

Amaç: Performans sporlarında antrenman planlamasının amacı hedef yarışmada istenilen performansi yakalamaktır. İstenen performansın da majör yarışmada gerçekleştirilmesi periyodizasyonun ana konusudur. Fakat bu noktada hazırlıkların vitrini niteliğinde olacak sezonun en iyi derecesinin gerçekleşeceği öngörüsü antrenörler için antrenman bilim tarihi kadar eski bir sorudur. Çalsşmanın amacı, uzun atlama branşında 2018 dünya listelerinde ilk yüz sirada yer alan kadın ve erkek sporcuların yarışma periyodundaki değişkenleri incelemek, cinsiyetlere göre karşılaştırmak, ilk iki performans ortalamasina göre sezonun en iyi ve ortalama performansları için tahmin modelleri oluşturmaktır. Metot: Çalışmada sporcuların yarışma verileri [yaş, bir sezondaki toplam gün sayıs1 (SGS), bir sezondaki toplam yarışma sayıs1 (TYS), sporcunun sezondaki en iyi derecesi (SB), SB performansının gerçekleştiği yanışma (SBY), sporcunun sezonun ilk iki yarışmasındaki performansinın ortalaması (İ2PO), sezon en iyi

\footnotetext{
1 Dr. Öğr. Üyesi, Aydın Adnan Menderes Üniversitesi, Spor Bilimleri Fakültesi, Antrenörlük Eğitimi Bölümü, bsutcu@adu.edu.tr (iD) Orcid ID: 0000-0003-0045-4881

2 Doç. Dr., Alanya Alaaddin Keykubat Üniversitesi, Spor Bilimleri Fakültesi, Antrenörlük Eğitimi Bölümü, isik.bayraktar@alanya.edu.tr (D) Orcid ID: 0000-0003-1001-5348
} 
Örs, B. S., \& Bayraktar, I. (2021). Uzun atlama branşında bir yarışma periyodunun sezon değişkenleri yönüyle değerlendirilmesi: Performans tahmin modellerinin oluşturulması. Journal of Human Sciences, 18(2), 331-341.. doi:10.14687/ihs.v18i2.6144

of competitions, the percentages of the first, end, and average scores were analysed. Statistical comparison of female and male athletes was carried out using Independent Samples t-Test. To express the relationships between parameters Pearson correlation coefficients (r) were used. Besides, polynomial regression analysis was used. Finally, the quadratic equations were used to predict $\mathrm{SB}$ performance and SPA according to the AF2P. Findings: SB competition, season initial, AF2P, SB, SPA and season-end variables were found to be statistically different between genders. Season initial and SB showed significant relationships for both genders (women; $\mathrm{r}=0.68 ; \mathrm{p}<0.001 ; \mathrm{men} ; \mathrm{r}=0.51$; $\mathrm{p}<0.001)$. AF2P explained $54 \%$ of the SB performance for women and $48 \%$ for men. Conclusion: The prediction model found in the current study to predict SB performance was applied to the male and female athletes from 2019 season. Models predicted the actual performance with an average of $1.15 \%$. Depending on the close estimation of the actual $\mathrm{SB}$ performance of the models; It is thought that the prediction models will enable the trainers to predict the performance of their athletes in target competitions at the beginning of the season.

Keywords: Periodization; prediction model; competition period; long jump; performance.

(Extended English summary is at the end of this document) derecesine göre; sezon ortalama ( $\left.\mathrm{S}_{\mathrm{ORT}}\right)$, başlang1c $\left(\mathrm{S}_{\mathrm{BAS}}\right)$ ve bitiriş $\left(\mathrm{S}_{\mathrm{BiT}}\right)$ derecelerinin yüzde oranlar1] incelenmiştir. Parametreler arasindaki ilişkiler için pearson korelasyon (r) istatistiği, ilişskilerin belirleme katsayılarının $\left(\mathrm{r}^{2}\right)$ bulunmasinda polinom regresyonu, cinsiyete göre İ2PO'dan SB ve sezon ortalama performanslarınin tahmin modellerinde karesel regresyon modeli kullanılmıştır. Bulgular: SBY,

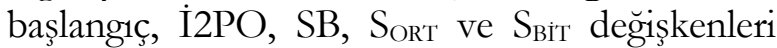
cinsiyetler arasinda istatistiksel olarak farklı bulunmuştur. $\mathrm{S}_{\mathrm{BASS}}$ değerleriyle SB performans1 arasında iki cinsiyet için anlamlı ilişkiler bulunmuștur (kadınlar; $\quad \mathrm{r}=0,68 ; \quad \mathrm{p}<0,001$; erkekler, $\mathrm{r}=0,51 ; \mathrm{p}<0,001)$. İ2PO; kadınlarda SB performansının \%54'ünü, erkeklerde; \%48’ini açıklayabilmektedir. Sonuç: Çalışmada bulunan İ2PO'na göre SB tahmin modeli, 2019 yilinda dünya listelerinde yer alan erkek ve kadın sporculara uygulandığında, modelin SB performansını ortalama \%1,15 farkla tahmin ettiğgi görülmüştür. Modellerin gerçek SB performansını yakın tahmin edebilmesine bağlı olarak; tahmin modellerinin antrenörlerin sezon başında sporcularının hedef yarışmalardaki performanslarını öngörebilmelerine olanak sağlayacağı düşünülmektedir.

Anahtar Kelimeler: Periyodizasyon; tahmin modeli; yarışma dönemi; uzun atlama; performans.

\section{Giriş}

Atletizmin yatay atlama branşlarından biri olan uzun atlamada amaç, sporcunun kendisine tanınan altı haktan birinde belirlenen $40 \mathrm{~m}$ koşu yolunun sonunda basma tahtasından sıçrayarak kum havuzuna doğru en uzak noktaya atlamaktır (Bayraktar \& Çilli, 2017; Nugraha et al., 2017; Tan \& Zumerchik, 2000). Bu şekilde komplike becerilerin kullanımını gerektiren bir performans ise iyi bir antrenman planlaması olmadan gerçekleştirilemez (Nugraha et al., 2017). Antrenman planları periyodizasyon ismi verilen formatta hazırlanır ve bu tür antrenmanlar belli zamanlar ve belli dönemler için planlanırlar. Periyodizasyon antrenmanları belirlenmiş hedefe ulaşmak için gerekli optimal sonucu elde etmek amaciyla antrenman adımlarının minimalleştirilmesidir (Bartolomei et al., 2014; Bompa \& Haff, 2015; Issurin, 2010; Nugraha et al., 2017). Literatürde periyodizasyon ile ilgili birçok tanım yer alır, eğer bu tanımlar özetlenecek olursa periyodizasyon spesifik bir amaç doğrultusunda antrenmanları planlamak ve organize etmektir (Açıkada, 2018). Periyodizasyonda amaç, hedeflenen zaman dilimlerinde (hedef yarışma gibi) optimal performans çıtıllarına 
Örs, B. S., \& Bayraktar, I. (2021). Uzun atlama branşında bir yarışma periyodunun sezon değişkenleri yönüyle değerlendirilmesi: Performans tahmin modellerinin oluşturulması. Journal of Human Sciences, 18(2), 331-341.. doi:10.14687/ihs.v18i2.6144

ulaşabilmektir (Haff, 2013). Spor bilimciler hedeflenen amaca ulaşmak yönünde branşa özel yapılan yıllık antrenman planlanması ile sporcuların yüksek performans seviyelerine çıkabileceği konusunda hemfikirdir. Bu sebeple, periyodizasyon konsepti ve performans gelişimi üzerindeki etkileri özellikle hedef yarışmalarda istenilen üst düzey performanslara ulaşmak için büyük önem taşır.

Diğer yandan, Olimpiyat Oyunlarından elde edilen sonuçlar, dünya rekorlan ve belirli bir yıldaki dünyanın en iyi performansları şeklindeki verilere erişilebilirlik, istenilen organizasyonlardaki performansların analizine olanak sağlar. Bu analizlerden performansın zaman içindeki değişimi belirlenebilirken aynı zamanda matematiksel metotlardan yararlanılarak oluşturulacak tahmin modelleri de performans takibi için kullanılabilir. Literatürde; atletizm branşı ile ilgili geçmiş performanslara bağlı tahmin modellerinin oluşturulduğu görülmektedir. Bu şekildeki tahmin modeli oluşturmak için yapılan çalışmaların birincil amacının herhangi bir branşta ulaşılabilecek sınırların belirlenmesiyle birlikte sporculara yeni ve ulaşabilecekleri gerçekçi amaçlar konması olduğu söylenebilir (Heazlewood, 2006). Buna ek olarak, sporcular için yarışmaların belirlenmesinde seçici olmak gerekir. Çünkü, hazırlık ve forma girmek için bazı atletler çok sayıda yarışmaya ihtiyaç duyarken; bazıları ise az sayıda yarışma isterler. Hazırlanan programların tüm bu ihtiyaçlara cevap vermesi gereklidir ve programlar hazırlanırken atletlerin antrenman düzeyine bağlı olarak iki veya üç hafta formda kalabileceği göz önünde bulundurulmalıdır (Açıkada \& Bayraktar, 2018). Marion Jones (100-200 m, uzun atlama), Sergei Bupka (sırıkla atlama), Stefka Kostadinova (yüksek atlama) gibi atletizmin farklı branşlarında Olimpiyat, Dünya şampiyonluğu olan sporcuların bir sezondaki yarışma gün sayılarına bakıldığında sırasıyla; 200 gün, 265 gün ve 165 gün olduğu görülmektedir (Issurin, 2008). Buna ek olarak, Örs ve Bayraktar (2020) atletizmin dikey atlama branşları (uzun atlama ve sırıkla atlama) için tahmin modeli oluşturdukları ve bir yarışma sezonu değişkenlerinin incelenmesini amaçladıkları çalışmalarında; sırıkla atlama için bir sezondaki maksimum yarışma sayısını erkeklerde 10,8; kadınlarda 10,0 olarak bulmuşlardır. Ayrıca, açık saha yarışları olarak kabul edilen ikinci yarışma sezonu evresinin tüm dikey atlama branşları için yaklaş1k 3.5-4 ay sürdügünü belirtmişlerdir. Aynı çalışmada sezonun en iyi derecesi (SB) ve sezonun ortalama derecesi için ilk iki performans ortalamasına bakarak tahmin modelleri oluşturulduğu da görülmektedir. Bu tahmin modellerine göre ilk iki performans ortalaması SB performansını yüksek atlama kadınlarda \%70, erkeklerde $\% 57$; sirikla atlama kadınlarda $\% 57$ ve sirikla atlama erkeklerde \%64 oranında açıklamaktadır. Sezon ortalama performansı için oluşturulan tahmin modelleri incelendiğinde ise; ilk iki performans ortalamasının sezon ortalama performansını yüksek atlama için kadınlar ve erkeklerde sırasıyla $\% 80$ ve $\% 62$ oranında; sırıkla atlamada $\% 73$ ve $\% 64$ oranında açıladığ belirtilmiştir.

Diğer olimpik branşlarda olduğu gibi, atletizmin atlamalar branşlarında da antrenman planlanmasının amacı hedef yarışmada istenilen performansı yakalamaktır. Sporcuların sezona başlama zamanları, sezon içerisinde katılacakları toplam yarışma sayısı, yarışma sıklıkları gibi değişkenler antrenörlerin antrenman planlaması yaparken göz önünde bulundurması gereken konuların başında gelir. Dünyanın ilk 100 sırasında yer alan elit sporcuların bir yarışma sezonlarının incelenmesinin ve sezonun ilk iki performansına bağlı sezonun en iyi derecelerinin tahmin modellerinin oluşturulmasının antrenörlere ve antrenman bilimcilere uzun atlama branşında bir yarışma dönemi planlaması konusunda fayda sağlayacağı düşünülmektedir. Tüm bu bilgiler doğrultusunda; çalışmanın amacı atletizmin yatay atlamalar sınıfina giren uzun atlama branşında yarışan ve 2018 dünya listelerinde ilk yüz sırada yer alan elit erkek ve kadın sporcuların yarışma periyodundaki farklı değişkenleri analiz etmek, cinsiyetlere göre karşılaştırmak, ilk iki performans ortalamasina göre sezonun en iyi ve sezonun ortalama performansları için tahmin modelleri oluşturmak olarak belirlenmiştir. 
Örs, B. S., \& Bayraktar, I. (2021). Uzun atlama branșında bir yarışma periyodunun sezon değişkenleri yönüyle değerlendirilmesi: Performans tahmin modellerinin oluşturulması. Journal of Human Sciences, 18(2), 331-341.. doi:10.14687/jhs.v18i2.6144

\section{Metot}

\section{1. Çalışmanın Verileri}

Çalışmanın verileri 2018 sezonunda uzun atlamada dünyada ilk yüz sırada yer alan elit erkek ve kadın sporcuların yarışma sezonu verilerinden oluşturulmuştur.

\subsection{Veri Toplanmasi}

Dünya listelerinde ilk yüz sırada yer alan elit atletlerin sezondaki yarışma bilgilerine World Athletics resmi internet sayfasında yayınlanan 2018 dünya sıralamaları listesinden ulaşılmıstır [(erkekler için: World Athletics (2019a), kadınlar için: World Athletics (2019b)]. Yaş, bir sezondaki toplam gün sayısı (SGS), bir sezondaki toplam yarışma sayısı (TYS), sporcunun sezondaki en iyi derecesi (SB), SB performansının gerçekleştiği yarışma (SBY), sporcunun sezonun ilk iki yarışmasındaki performansının ortalaması (İ2PO), sezon en iyi derecesine göre (SB) sezon ortalama ( $\left.\mathrm{S}_{\mathrm{ORT}}\right)$, sezon başlangıç $\left(\mathrm{S}_{\mathrm{BASS}}\right)$ ve sezon bitiriş $\left(\mathrm{S}_{\mathrm{BiT}}\right)$ derecelerinin yüzde oranları hesaplanmıştur.

\section{3. Çalısmanın Etik Yönü}

Bu çalışma, kamuya açık verilerle gözlemsel bir çalışma olarak yapılmıştır. Çalışma verileri World Athletics resmi internet sitesinden elde edilmiştir. Çalışma verileri, işlenmemiş bir formatta çevrimiçi olarak mevcut olduğundan ve deney yoluyla toplanmadığından, Morley ve Thomas (2005) tarafından belirtildiği gibi etik kaygı taşımamaktadır.

\subsection{Istatistiksel Analizler}

İstatistik analizler için IBM-SPSS 20.0 yazılımı kullanılmıştır. Katılımcıların genel karakteristik özellikleri ortalama karşılaştırma bağımsız örneklemler $t$ testi ile yapılmıştır. Pearson korelasyon (r) istatistiği değişkenler arasındaki ilişkileri açıklamak için kullanılmıştır. İlişki düzeyleri yorumlanırken: $r \leq 0,49$ zayıf ilişki; $0,50 \leq r \leq 0,74$ orta ilişki ve $r \geq 0,75$ yüksek ilişki olarak kabul edilmiştir (Portney \& Watkins, 2015). İlişkiler için belirleme katsayılarının $\left(\mathrm{r}^{2}\right)$ bulunması için polinom regresyonu kullanılmıştır. Cinsiyete göre sezon başındaki ilk iki performanstan $\mathrm{SB}$ ve $\mathrm{S}$ ORT performanslarının tahmin edilmesi için karesel regresyon modeli kullanılmıştır. Anlamlılık düzeyi $\mathrm{p}<0,05$ olarak kabul edilmiştir.

\section{Bulgular}

Tablo 1'de uzun atlama branşı için yaş ve yarışma sezon değişkenlerinin ortalama sapma değerleri verilmiştir. Ayrıca, aşağıdaki tablolarda değişkenlerin cinsiyetlere göre karşılaştırma sonuçları da verilmiştir (Tablo 2-4).

Tablo 1. Cinsiyete göre tanımlayıcı istatistikler ve sezon değişkenleri

\begin{tabular}{|c|c|c|c|}
\hline \multirow{2}{*}{ Değişkenler } & \multicolumn{2}{|c|}{ Ortalama \pm Standart Sapma } & \multirow[b]{2}{*}{$\mathrm{p}$} \\
\hline & $\begin{array}{l}\text { Erkek } \\
(n=100)\end{array}$ & $\begin{array}{c}\text { Kadın } \\
(n=100)\end{array}$ & \\
\hline Yaş (yll) & $24,7 \pm 4,1$ & $25,7 \pm 4,5$ & 0,09 \\
\hline SGS (gün) & $128,8 \pm 59,2$ & $114,2 \pm 47,7$ & 0,06 \\
\hline Yarışma Sıklı̆ğ1 & $13,7 \pm 6,4$ & $13,4 \pm 6,1$ & 0,79 \\
\hline TYS & $10,1 \pm 4,0$ & $9,2 \pm 3,7$ & 0,13 \\
\hline SBY & $5,8 \pm 56$ & $4,9 \pm 2,9$ & $0,04^{*}$ \\
\hline$\% \mathrm{SBY}$ & $58,0 \pm 26,5$ & $52,9 \pm 24,1$ & 0,16 \\
\hline$\%$ Başlangıç & $95,5 \pm 2,9$ & $95,8 \pm 3,1$ & 0,44 \\
\hline$\%$ Bitiriş & $95,6 \pm 3,7$ & $95,2 \pm 2,9$ & 0,37 \\
\hline$\%$ Ortalama & $96,2 \pm 1,3$ & $96,3 \pm 1,5$ & 0,51 \\
\hline
\end{tabular}

SS: Standart Sapma; SGS: Bir sezondaki toplam gün sayısi; TYS: Bir sezondaki toplam yarısma sayısi; SBY: Sezonun en iyi performansinm gerçeklestiüi yarısma; $S_{B A s:}$ Sezon baslangıc derecesi; SoRT: Sezon ortalama derecesi; SBiT: Sezon bitiriş derecesi; SB: Sezonun en iyi derecesi; İPO: Sporcunun sezonun ilk iki yarısmasmdaki performansinin ortalamast 
Örs, B. S., \& Bayraktar, I. (2021). Uzun atlama branșında bir yarışma periyodunun sezon değişkenleri yönüyle değerlendirilmesi: Performans tahmin modellerinin oluşturulması. Journal of Human Sciences, 18(2), 331-341.. doi:10.14687/jhs.v18i2.6144

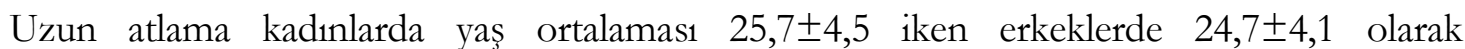
bulunmuştur. SBY, başlangıç, İ2PO, SB, ortalama ve bitiriş değişkenleri cinsiyetler arasında istatistiksel olarak anlamlı farklılık göstermiştir $(\mathrm{p}<0,05)$.

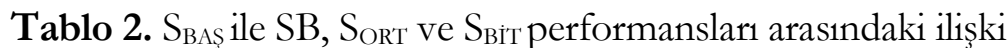

\begin{tabular}{ccccc}
\hline $\mathbf{S}_{\text {BAŞ }}$ & & SB & S $_{\text {ORT }}$ & $\mathbf{S}_{\text {BíT }}$ \\
\hline Erkek & $\mathrm{r}$ & $0,51^{*}$ & $0,66^{*}$ & 0,18 \\
$(n=100)$ & $\mathrm{p}$ & $\mathrm{p}<0,001$ & $\mathrm{p}<0,001$ & $\mathrm{p}<0,001$ \\
Kadın & $\mathrm{r}$ & $0,68^{*}$ & $0,81^{*}$ & $0,52^{*}$ \\
$(n=100)$ & $\mathrm{p}$ & $\mathrm{p}<0,001$ & $\mathrm{p}<0,001$ & $\mathrm{p}<0,001$ \\
\hline
\end{tabular}

$S_{B A s ̧:}$ Sezon başlangıs derecesi; SB: Sporcunun sezondaki en iyi derecesi; $S_{\text {ORT: }}$ Sezon ortalama derecesi; $S_{B I T}$ : Sezon bitiriş derecesi

Sezon başlangıç değerleri ile SB performansı arasındaki ilişkilere bakıldığında her iki cinsiyet için de istatistiksel olarak anlamlı, pozitif ve orta düzeyde ilişkiler bulunmuştur (kadınlar için r=0,68; $\mathrm{p}<0,001$; erkekler için $\mathrm{r}=0,51 ; \mathrm{p}<0,001)$. Bununla birlikte, sezon başlangıç performansının her iki cinsiyet için de SB, sezon ortalama ve bitiriş performanslanı ile istatistiksel olarak anlamlı ve pozitif ilişkiler gösterdiği bulunmuştur.

Tablo 3. İ2PO ile $\mathrm{SB}, \mathrm{S}_{\mathrm{ORT}}$ ve $\mathrm{S}_{\text {Biт }}$ performansları arasındaki ilișki

\begin{tabular}{ccccc}
\hline İ2PO & & SB & S $_{\text {ORT }}$ & S $_{\text {BіT }}$ \\
\hline Erkek & $\mathrm{r}$ & $0,60^{*}$ & $0,74^{*}$ & 0,13 \\
$(n=100)$ & $\mathrm{p}$ & $\mathrm{p}<0,001$ & $\mathrm{p}<0,001$ & 0,18 \\
Kadin & $\mathrm{r}$ & $0,68^{*}$ & $0,81^{*}$ & $0,52^{*}$ \\
$(n=100)$ & $\mathrm{p}$ & $\mathrm{p}<0,001$ & $\mathrm{p}<0,001$ & $\mathrm{p}<0,001$ \\
\hline
\end{tabular}

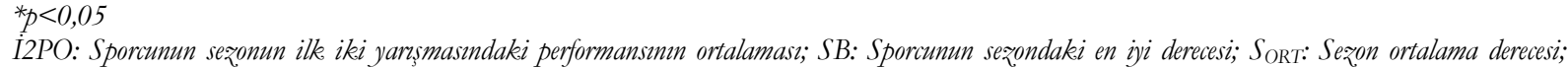

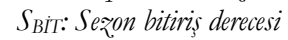

Hem kadınlar hem erkekler için ilk iki performans ortalaması ile SB, sezon ortalama ve sezon bitiriş performansları arasındaki ilişkiler incelendiğinde anlamlı ve pozitif ilişkiler olduğu bulunmuştur.

Tablo 4. SB ile yaş, SGS, yarış sıklı̆̆ı ve TYS arasındaki ilişkiler

\begin{tabular}{cccccc}
\hline SB & & Yaş & SGS & Yarış S1klı̆̆ & TYS \\
\hline Erkek & $\mathrm{r}$ & $-0,06$ & 0,14 & 0,11 & 0,04 \\
$(n=100)$ & $p$ & 0,59 & 0,17 & 0,26 & 0,67 \\
Kadin & $\mathrm{r}$ & 0,16 & 0,02 & $-0,18$ & 0,19 \\
$(n=100)$ & $p$ & 0,10 & 0,81 & 0,07 & 0,05 \\
\hline SGS: Sezon Toplam Gün Sayısi; TYS: Toplam Yarıșma Sayısi; SB: Sez̧onun En Iyi Derecesi
\end{tabular}

Tablo 4’te sporcuların SB dereceleri ile yaş, SGS, yarış sıklı̆̆ı ve TYS değişkenleri arasındaki ilişkiler incelendiğinde istatistiksel olarak anlaml ilişkiler gözlenmemiştir.

İstatistiksel analiz sonuçlarına göre; ilk iki performans ortalaması değişkeni SB ve sezon ortalama performanslarını tahmin etmek için kullanılmıştır. Bu performansları tahmin etmede kullanılabilecek tahmin denklemleri aşağıda verilmiştir:

I. İlk iki performans ortalaması ve SB performansı değişkenleri arasında karesel regresyon modeli uygulanmış ve yüksek düzeyde pozitif ilişki bulunmuştur. Buna göre;

a) Kadınlarda; İ2PO SB performansının \%54'ünü açıklayabilmektedir ( $<<0,001)$. Başka bir deyişle, SB performansının \%54’ü İ2PO'na bağlıdır.

İ2PO'na göre SB tahmin denklemi: 
Örs, B. S., \& Bayraktar, I. (2021). Uzun atlama branşında bir yarışma periyodunun sezon değişkenleri yönüyle değerlendirilmesi: Performans tahmin modellerinin oluşturulması. Journal of Human Sciences, 18(2), 331-341.. doi:10.14687/jhs.v18i2.6144

$$
\mathrm{SB}=22,801+(\text { İ2PO } \mathrm{x}-5,548)+\left[\left(\mathrm{I}_{2} \mathrm{PO}\right)^{2} \times 0,472\right]
$$

b) Erkeklerde; İ2PO SB performansının \%48’ini açılayabilmektedir ( $\mathrm{p}<0,001)$. Başka bir deyişle, SB performansının \%48’i İ2PO'na bağlıdır.

İ2PO'na göre SB tahmin denklemi:

$$
\mathrm{SB}=41,366+(\mathrm{I} 2 \mathrm{PO} \mathrm{x}-9,037)+\left[(\dot{\mathrm{I}} 2 \mathrm{PO})^{2} \times 0,611\right]
$$
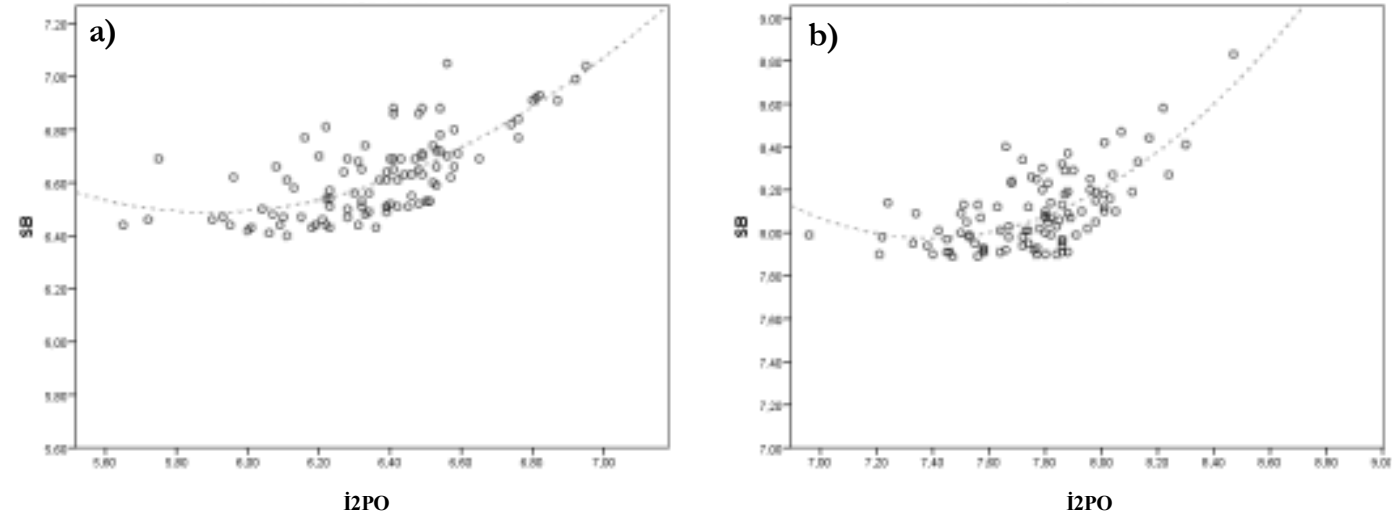

Grafik 1. SB ve İ2PO arasındaki ilişki grafikleri (a: Kadınlar, b: Erkekler)

II. İlk iki performans ortalaması ve sezon ortalama performansı değişkenleri karesel regresyon modeli uygulanmış ve yüksek düzeyde pozitif ilişki bulunmuştur. Buna göre;

c) Kadınlarda; İ2PO sezon ortalama performansının \%78'ini açılayabilmektedir $(\mathrm{p}=0,021)$. Başka bir deyişle, sezon ortalama performansının \%78’i İ2PO’na bağlıdır.

İ2PO'na göre SoRT performansı tahmin denklemi:

$$
\text { Sezon Ortalama Performans1 }=12,521+(\dot{\mathrm{I}} 2 \mathrm{PO} \mathrm{x}-2,563)+\left[(\dot{\mathrm{I}} 2 \mathrm{PO})^{2} \mathrm{x} 0,251\right]
$$

d) Erkeklerde; İ2PO sezon ortalama performansının \%59'unu açılayabilmektedir ( $\mathrm{p}=0,006)$. Başka bir deyişle, sezon ortalama performansının \%59'u İ2PO’na bağlıdır. İ2PO'na göre $\mathrm{S}_{\text {ORT }}$ performansı tahmin denklemi:

Sezon Ortalama Performans $1=25,396+($ İ2PO x $-5,104)+\left[(\text { İ2PO })^{2}\right.$ x 0,365]
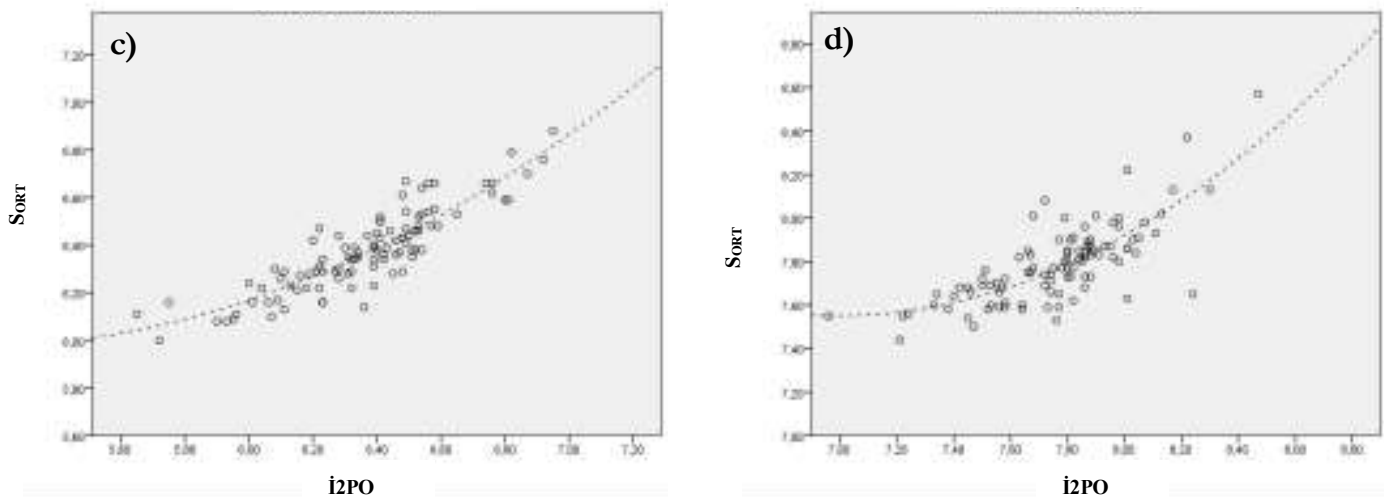

Grafik 2. S ORT ve İ2PO arasındaki ilişki grafikleri (c: Kadınlar, d: Erkekler için) 
Örs, B. S., \& Bayraktar, I. (2021). Uzun atlama branșında bir yarışma periyodunun sezon değişkenleri yönüyle değerlendirilmesi: Performans tahmin modellerinin oluşturulması. Journal of Human Sciences, 18(2), 331-341.. doi:10.14687/ihs.v18i2.6144

2019 yilında Dünya listelerinde yer alan erkek (10 sporcu) ve kadın (10 sporcu) sporcuların bu çalışmada bulunan İ2PO'na göre SB tahminleri ve SB dereceler Tablo 5’te verilmiştir. Ayrıca, SB performansı ile tahmin edilen performans arasındaki fark yüzdeleri de Tablo 5’te belirtilmiştir.

Tablo 5. 2019 yılı erkek ve kadın sporcuların İ2O'na göre SB dereceleri, SB tahminleri, $\mathrm{S}_{\text {ORT }}$ dereceleri, $S_{\text {ORT }}$ tahminleri ve aradaki fark yüzdesi

\begin{tabular}{|c|c|c|c|c|c|c|c|c|}
\hline Branş & Sporcu & $\dot{I} 2 P O$ & $S_{O R T}$ & $S B$ & $\begin{array}{c}\text { I2PO ile } \\
\text { Tahmin } \\
\text { Edilen } \\
\quad S B\end{array}$ & $\begin{array}{c}\text { SB ile } \\
\text { Tahmin } \\
\text { Edilen } \\
\text { Performans } \\
\text { Arasindaki } \\
\text { Fark }\end{array}$ & $\begin{array}{c}\text { İPO İle } \\
\text { Tahmin } \\
\text { Edilen } \\
S_{\text {ORT }}\end{array}$ & $\begin{array}{c}\text { SORT Tahmin } \\
\text { Edilen } \\
\text { Performans } \\
\text { Arasindaki } \\
\text { Fark }\end{array}$ \\
\hline \multirow{5}{*}{ 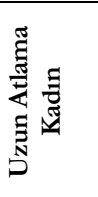 } & Ese BRUME & 6,86 & 6,88 & 7,05 & 6,95 & $\% 1,4$ & 6,75 & $\% 1,9$ \\
\hline & Brittney REESE & 6,87 & 6,79 & 7,01 & 6,96 & $\% 0,7$ & 6,76 & $\% 0,4$ \\
\hline & Florentina Costina IUSCO & 6,73 & 6,60 & 6,92 & 6,84 & $\% 1,2$ & 6,64 & $\% 0,6$ \\
\hline & Ivana ŠPANOVIĆ & 6,60 & 6,70 & 6,85 & 6,74 & $\% 1,6$ & 6,54 & $\% 2,5$ \\
\hline & Katarina JOHNSON-THOMPSON & 6,56 & 6,66 & 6,85 & 6,71 & $\% 2,1$ & 6,51 & $\% 2,3$ \\
\hline \multirow{5}{*}{ 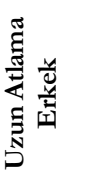 } & Juan Miguel ECHEVARRÍA & 8,44 & 8,34 & 8,65 & 8,61 & $\% 0,5$ & 8,32 & $\% 0,3$ \\
\hline & Luvo MANYONGA & 8,26 & 8,17 & 8,37 & 8,4 & $\% 0,4$ & 8,14 & $\% 0,4$ \\
\hline & Miltiadis TENTOGLOU & 8,04 & 8,03 & 8,32 & 8,2 & $\% 1,5$ & 7,95 & $\% 1,0$ \\
\hline & Yuki HASHIOKA & 8,03 & 8,01 & 8,32 & 8,2 & $\% 1,5$ & 7,95 & $\% 0,8$ \\
\hline & Andwuelle WRIGHT & 8,04 & 7,89 & 8,25 & 8,2 & $\% 0,6$ & 7,95 & $\% 0,8$ \\
\hline
\end{tabular}

\section{Tartışma}

Bu çalışmada, atletizmin uzun atlama branşında dünya listelerinde ilk 100 sırada yer alan kadın ve erkek sporcuların yarışma periyodundaki farklı değişkenler cinsiyetlere göre karşılaştırılmıştır. Ayrıca, sezonun ilk iki performansının ortalamasına göre sezonun en iyi ve ortalama performansları için tahmin denklemleri oluşturulmuştur. Çalışmanın sonuçlarına göre; $\mathrm{SBY}, \mathrm{S}_{\mathrm{BASS}}$, İ2PO, SB, S $\mathrm{S}_{\text {ORT }}$ ve $\mathrm{S}_{\text {Biт }}$ değişkenleri cinsiyetler arasında istatistiksel olarak anlamlı farklılıklar göstermiştir. Ayrıca, sporcuların sezon başında gösterdiği ilk iki performansın ortalamasinın, kadınlarda SB performansının \%54'ü ve erkeklerde ise SB performansinın \%48'ini açıkladığı bulunmuştur. Aynı şekilde sporcuların yarışma sezonundaki ilk iki performanslarının ortalamas1, sporcuların tüm sezon boyunca katıldıkları yarışmalardaki ortalama performanslarını kadınlarda $\% 78$ ve erkeklerde ise $\% 59$ oranında açıklayabildiği tespit edilmiştir.

Literatürde, Örs ve Bayraktar (2020) atletizmin dikey atlama branşlarnnda (yüksek atlama ve sırıkla atlama) elit sporcuların bir yarışma periyodunu değerlendirdikleri çalışmalarında yüksek atlama branşında sezon gün sayısını erkekler için 112,4 ve kadınlar için 107,1 olarak belirtmişlerdir. Bununla birlikte, aynı değişken sırıkla atlama branşı için incelendiğinde; bu değerin erkeklerde 113,6 ve kadınlarda 105,3 olduğu görülmüştür. Uzun atlama branşında yarışan elit erkek ve kadın sporcuların sezon performans değişkenlerinin incelendiği bu çalışmada ise sezon gün sayısı erkekler için 128,8 ve kadınlar için 114,2 olarak bulunmuştur. Atletizmin yatay atlama branşlarından olan uzun atlama için bulunan sezondaki gün sayısı değişkeni dikey atlamalara göre daha yüksektir. Yüksek atlama ve sırıkla atlama branşlarının teknik açıdan uzun atlamaya göre daha komplike bir yapıya sahip olmasına bağlı olarak; uzun atlama branşında sporcuların diğer branşlara göre daha hızlı bir toparlanma süreci geçirip, daha fazla sayıda yarışa katılabildiği yorumu yapılabilir.

Modern bilim çağında, sporcular, branşlarında daha iyi başarılar elde etmek ve daha yüksek standartlara ulaşmak için yararlı olduğu kanıtlanmış oldukça karmaşı yöntemlerle antrene edilir (Fattah \& Bataineh, 2020). Yarışma dönemlerinin süresinin ve yarışma sayısının farklı spor branşlarına göre değişiklik gösterebileceği, her branşın farklı periyodizasyon ihtiyacı olduğu da bilinir (Hartmann et al., 2015). Spor branşına ve sporcunun karakterine bağlı olarak ylllık antrenman planlaması yapılırken birkaç değişken vardır. Genel olarak, yarışma dönem sayısı yıllık planda makrosiklüslerin sayısını belirlemek için temel oluşturur (Naclerio et al., 2013). Literatürde bir 
Örs, B. S., \& Bayraktar, I. (2021). Uzun atlama branşında bir yarışma periyodunun sezon değişkenleri yönüyle değerlendirilmesi: Performans tahmin modellerinin oluşturulması. Journal of Human Sciences, 18(2), 331-341.. doi:10.14687/ihs.v18i2.6144

yarışma sezonu boyunca elit atletlerin katıldı̆̆ yarışma sayısını inceleyen bazı çalışmalar bulunmaktadır (B. S. Örs \& Bayraktar, 2020; T. Örs et al., 2019). Elit uzun atlayıcıların bir sezon boyunca yarışma sayıları incelendiğinde erkeklerde ortalama 10,1 kadınlarda ise 9,2 yarışma olduğu görülmektedir. Buna ek olarak, (T. Örs et al., 2019) elit sprinterlerin bir sezon boyunca ortalama yarış sayılarının erkeklerde 13,1 ve kadınlarda 11,4 olduğunu bulmuştur. Aynı değişkeni yüksek atlama için inceleyen bir diğer çalışma ise bu değerin erkeklerde 8,8, kadınlarda 9,1 olduğunu belirtmiştir (Örs ve Bayraktar, 2020). Uzun atlama branşında yarışan dünyanın ilk 100 sırasında yer alan erkek ve kadın sporcuların bir sezon boyunca yarıştıkları yarışma sayısının incelendiği bu çalışmada; toplam yarışma sayısı erkeklerde 10,1 ve kadınlarda 9,2 olarak bulunmuştur. Birçok spor branşında, uluslararası spor federasyonlarının elit ve sub-elite sporcular için yarışma sayılarını arttırmasına bağlı olarak; üst düzey sporcuların yarışma sayılarının da arttı̆̆1 görülür. Bunun sonucunda da, üst düzey sporcular eskisine göre daha fazla yarışa katılmaktadır (Issurin, 2008). Ayrıca, bazı çalışmalar sporcuların maksimal performans öncesi 7-10 arasında yarışmaya katılmaları gerektiğini belirtmektedir (Gandelsman ve Smirnov, 1970; aktaran Bompa, 1994). Bu bilgiler doğrultusunda, çalışmanın sonuçlarının literatürü destekler nitelikte olduğu görülmüştür.

Bilgimiz dahilinde literatürde uzun atlamaya yönelik model çalışması olmadığı için sonuçlar atletizmin dikey atlama branşları ile karşılaştırlmıştır. Sezonun en iyi derecesi (SB) ve sezonun ortalama derecesi için ilk iki performans ortalamasına bakarak tahmin modellerinin oluşturulduğu bir çalışmada (2018 sezonu için); ilk iki performans ortalamasının SB performansını yüksek atlama kadınlarda $\% 70$, erkeklerde $\% 57$; sirıkla atlama kadınlarda $\% 57$ ve sirikla atlama erkeklerde $\% 64$ oranında açıkladığı bulunmuştur. Ayrıca, sezon ortalama performansı için oluşturulan tahmin modelleri incelendiğinde ise; ilk iki performans ortalamasının sezon ortalama performansını yüksek atlama için kadınlar ve erkeklerde sırasıyla $\% 80$ ve $\% 62$ oranında; sırıkla atlamada $\% 73$ ve $\% 64$ oranında açıkladığı belirtilmiştir. Aynı çalışmada oluşturulan tahmin modelleri 2019 yılında ilk onda yer alan beş kadın ve beş erkek atlete uygulandığında modelin SB performansını yüksek atlama erkeklerde $\% 0,6$, kadınlarda \%0,8; sırıkla atlama erkeklerde $\% 0,7$, kadınlarda $\% 0,4$ oranında gerçek performanstan sapma ile tahmin ettiği bulunmuştur. S ОRт performansı ise yüksek atlama erkeklerde $\% 0,6$, kadınlarda $\% 0,46$; sırıkla atlama erkeklerde $\% 0,62$, kadınlarda $\% 0,84$ farkla tahmin edilmisstir (B. S. Örs \& Bayraktar, 2020). Mevcut çalışmada oluşturulan tahmin modelleri 2019 yllında ilk on sıralamada yer alan beş kadın ve beş erkek sporcuya uygulandığında modelin SB performansını $\% 1,4$ ve $\% 0,9$ sapma ile tahmin ettiği bulunmuştur. Ayrıca, tahmin modelleri $\mathrm{S}_{\text {ORT }}$ performansının erkeklerde \%0,66 ve kadınlarda \%1,54 sapma ile sezon ortalama performansını tahmin ettiği görülmüştür. Bu sonuçlara bağlı olarak; gerçek performanstan sapmaların oranına bakarak antrenörlerin sporcularının performanslarını tahmin etmede ve antrenman planlamalarını yapılandırmada bu çalışmada elde edilen tahmin modellerinden yararlanabileceği söylenebilir.

\section{Sonuç}

Sezon başlangıcında sporcuların sergilediği ilk iki performansın ortalamasına bağlı olarak sezonun en iyi derecesini tahmin etmede kullanılacak tahmin modelleri antrenörler için tüm sezonu ön görebileceği erken bir değerlendirme olarak düşünülebilir. Çalısmada ortaya konulan tahmin modellerine göre sporcuların performanslarını sezon başında takip edip, sezonun en iyi derecesi tahmin edilerek olası bir hedef performanstan uzaklaşma söz konusu olduğunda antrenörlerin sezon başında gerekli önlemleri alması mümkün olacaktır. Böyle bir durumda, bu tahmin modellerine göre, sezon planlaması yeniden gözden geçirilebilir.

Bu çalışmada bulunan I2PO'na göre SB tahmin modeli, 2019 yllında dünya listelerinde yer alan ve rastgele seçilen beş erkek ve beş kadın sporcuya uygulandığında, modelin SB performansını erkeklerde ortalama $\% 0,9$ ve kadınlarda ortalama $\% 1,4$ farkla tahmin ettiği görülmüştür. Buna ek olarak, sezon başındaki ilk iki performans ortalamasına göre $\mathrm{S}_{\text {ORT }}$ performans tahmin modelleri de 2019 yllında dünya listelerinde yer alan beş kadın ve beş erkek sporcuya uygulanmıştır. S performansinın erkeklerde $\% 0,66$ ve kadınlarda \%1,54 sapma ile sezon ortalama performansını 
Örs, B. S., \& Bayraktar, I. (2021). Uzun atlama branșında bir yarışma periyodunun sezon değişkenleri yönüyle değerlendirilmesi: Performans tahmin modellerinin oluşturulması. Journal of Human Sciences, 18(2), 331-341.. doi:10.14687/jhs.v18i2.6144

tahmin ettiği görülmüştür. Modellerin gerçek SB ve $\mathrm{S}_{\text {ORT }}$ performanslarını bu kadar yakın fark yüzdesi ile tahmin edebilmesine bağlı olarak bu tahmin modellerinin antrenörlerin sezon başında sporcularının hedef yarışmalardaki performanslarını öngörebilmeleri ve buna göre antrenman/yarışma periyotlaması yapabilmelerine olanak sağlayacağı düşünülmektedir.

$\mathrm{Bu}$ çalışma uzun atlama branşında yarışan yüz kadın ve yüz erkek sporcunun 2018 sezonundaki yarışma dönemi değişkenleri ile sınırlıdır. Benzer çalışmaların, atletizmin diğer branşlarında da uygulanmasının yarışma dönemi ve periyodizasyonu ile ilgili yararlı bilgiler sağlayacağ1 düşünülmektedir. Buna ek olarak, benzer yarışma dönemi incelemelerinin yüzme, cimnastik gibi branşlarda da yapılmasının hem antrenörlere hem de literatüre katkı sağlayacağı düşünülmektedir.

\section{Referanslar}

Açıada, C. (2018). Antrenman Bilimi. Antrenman ilkeleri, periyodizasyon ve form antrenmanlar. Spor Yayınevi.

Açıada, C., \& Bayraktar, I. (2018). Atletizmde Periodizasyon Stratejileri. In Antrenman Bilimi (1st ed.). Spor Yayınevi.

Bartolomei, S., Hoffman, J. R., Merni, F., \& Jeffrey, R. S. (2014). A comparison of traditional and block periodized strength training programs in trained athletes. 28(4), 990-997.

Bayraktar, I., \& Çilli, M. (2017). Uzun ve üsadom branşlarnda biyomekanik analiəler. Nobel Akademik Yayıncilik.

Bompa, T. (1994). Theory and Methodology of Training: The Key To Athletic Performance. Hunt Publishing Company.

Bompa, T., \& Haff, G. G. (2015). Dönemleme: Antrenman Kuramı ve Yöntemi (Ç. T. Bağırgan (ed.)). Spor Yayinevi.

Fattah, O. A., \& Bataineh, A. S. (2020). Analysis of kinematics of the approach run in long jump event among jordanian male team. Russian Journal of Biomechanics, 24(1), 15-22. https://doi.org/10.15593/RJBiomech/2020.1.02

Haff, G. G. (2013). Periodization strategies for youth development. Strength and Conditioning for Young Athletes: Science and Application (R. L. and J. Oliver (ed.)).

Hartmann, H., Wirth, K., Keiner, M., Mickel, C., Sander, A., \& Szilvas, E. (2015). Short-term Periodization Models: Effects on Strength and Speed-strength Performance. Sports Medicine, 45(10), 1373-1386. https://doi.org/10.1007/s40279-015-0355-2

Heazlewood, T. (2006). Prediction versus reality: The use of mathematical models to predict elite performance in swimming and athletics at the Olympic Games. Journal of Sports Science and Medicine, 5(4), 541-547.

Issurin, V. B. (2008). Block periodization versus traditional training theory: A review. Journal of Sports Medicine and Physical Fitness, 48(1), 65-75.

Issurin, V. B. (2010). New Horizons for the Methodology and Physiology of Training Periodization. Sports Med, 40(3), 189-206.

Morley, B., \& Thomas, D. (2005). An investigation of home advantage and other factors affecting outcomes in English one-day cricket matches. Journal of Sports Sciences, 23(3), 261-268. https://doi.org/10.1080/02640410410001730133

Naclerio, F., Moody, J., \& Chapman, M. (2013). Applied periodization: A methodological approach. Journal of Human Sport and Exercise, 8(2 SUPPL), 350-366. https://doi.org/10.4100/jhse.2012.82.04

Nugraha, E., Dliss, F., \& Asmawi, M. (2017). Long jump training programs for Indonesian athletes. In IOP Conference Series: Materials Science and Engineering, 180(1), 1-7. https://doi.org/10.1088/1742-6596/755/1/011001

Örs, B. S., \& Bayraktar, I. (2020). A Competition Period Evaluation Concerning Seasonal Variables 
Örs, B. S., \& Bayraktar, I. (2021). Uzun atlama branșında bir yarışma periyodunun sezon değişkenleri yönüyle değerlendirilmesi: Performans tahmin modellerinin oluşturulması. Journal of Human Sciences, 18(2), 331-341.. doi:10.14687/jhs.v18i2.6144

of Elite Track and Field Athletes in Vertical Jumping Events: A Different Insight for Coaching Education. Journal of Educational Issues, 6(1), 439. https://doi.org/10.5296/jei.v6i1.17258

Örs, T., Bayraktar, I., Demir, M. O., \& Örs, B. S. (2019). Elit sprinterlerin bir yarışma periyodunun değerlendirilmesi: 100 metre branş örneği. II. Dünya Spor Bilimleri Kongresi, 830-837.

Portney, L. G., \& Watkins, M. P. (2015). Foundations of clinical research. Applications to practice (3rd ed.). F. A. Davis Company.

Tan, A., \& Zumerchik, J. (2000). Kinematics of the long jump. The Physics Teacher, 38(3), 147-149. https://doi.org/10.1119/1.880478

World Athletics (2019a): https://www.worldathletics.org/records/toplists/jumps/longjump/outdoor $/ \mathrm{men} /$ senior $/ 2018$ ?regionType $=$ world\&windReading $=$ regular\&page $=1 \&$ be stResultsOnly=true 10 Şubat 2019 tarihinde erişildi

World Athletics (2019b): $\quad$ https://www.worldathletics.org/records/toplists/jumps/longjump/outdoor/women/senior $/ 2018$ ? regionType $=$ world\&windReading $=$ regular\&page $=1 \&$ bestResultsOnly=true 10 Şubat 2019 tarihinde erişildi

\section{Extended English Summary}

\section{Introduction}

The long jump (LJ) aims to jump from the take-off board to the furthest point at the end of the determined $40 \mathrm{~m}$ approach run path in one of the six from six legal jumps (Bayraktar \& Ciilli, 2017; Nugraha et al., 2017; Tan \& Zumerchik, 2000). Such achievement could not be achieved without a good training plan (Nugraha et al., 2017). Variables such as the beginning time of the season, the total number and the frequency of the competitions are among main issues that trainers should consider when planning their training. It is thought that analysing a competition season of the elite athletes, and creating prediction models depending on the first two performance average of the season (AF2P) will help trainers and training scientists to plan a competition period for long jump event. This study aimed to determine the relationships of elite long jumpers' competition season variables in long jump events. Besides, it was aimed to create prediction models of seasonbest (SB) and season performance average (SPA) based on AF2P.

\section{Methods}

Research data constituted of elite athletes' (top hundreds in long jump in the 2018 season, female and male long jumpers) season variables. Ages, total number of days in a season, the number of days between the competitions, total competitions, and the number of competitions in which the season's best (SB) performance was achieved, the ratio of the SB to the total number of competitions, the percentages of the first, end, and average scores were analysed.

\section{Statistical Analysis}

Statistical comparison of female and male athletes was carried out using Independent Samples t-Test. To express the relationships between parameters Pearson correlation coefficients (r) were used. Besides, polynomial regression analysis was used. Finally, the quadratic equations were used to predict SB performance and SPA according to the AF2P.

\section{Results}

The mean age for women was found to be $25.7 \pm 4.5$ years while the mean age for men was 24.7 \pm 4.1 years. SB competition, season initial performance, AF2P, SB, season average, and seasonend variables were statistically different between women and men $(p<0.05)$. Season initial and SB performances showed significant correlations (female long jumpers: $r=0.68 ; p<0.001$; male long 
Örs, B. S., \& Bayraktar, I. (2021). Uzun atlama branșında bir yarışma periyodunun sezon değişkenleri yönüyle değerlendirilmesi: Performans tahmin modellerinin oluşturulması. Journal of Human Sciences, 18(2), 331-341.. doi:10.14687/jhs.v18i2.6144

jumpers: $\mathrm{r}=0.51 ; \mathrm{p}<0.001)$. AF2P was found to be statistically significant $\mathrm{SB}$, season mean, and season end performances $(\mathrm{p}<0.05)$.

In female LJ, AF2P explained 54\% of the SB performance. The SB prediction model based on $\mathrm{AF} 2 \mathrm{P}$ for female long jumpers was found as follows:

$\mathrm{SB}=22.801+(\mathrm{AF} 2 \mathrm{P} \times-5.548)+\left[(\mathrm{AF} 2 \mathrm{P})^{2} \times 0.472\right]$

In male LJ, AF2P explained $48 \%$ of the $\mathrm{SB}$ performance. The SB prediction model based on $\mathrm{AF} 2 \mathrm{P}$ for male long jumpers was found as follows:

$\mathrm{SB}=41.366+(\mathrm{AF} 2 \mathrm{P} \mathrm{x}-9.037)+\left[(\mathrm{AF} 2 \mathrm{P})^{2} \times 0.611\right]$

In female LJ, AF2P explained $78 \%$ of the SPA. The SPA prediction model based on AF2P for female long jumpers was found as follows:

$\mathrm{SPA}=12.521+(\mathrm{AF} 2 \mathrm{P} \times-2.563)+\left[(\mathrm{AF} 2 \mathrm{P})^{2} \times 0.251\right]$

In male LJ, AF2P explained 59\% of the SPA. The SPA prediction model based on AF2P for male long jumpers was found as follows:

$\mathrm{SPA}=25.396+(\mathrm{AF} 2 \mathrm{P} \times-5.104)+\left[(\mathrm{AF} 2 \mathrm{P})^{2} \times 0.365\right]$

\section{Discussion}

Ors et al. (2019) reported that elite sprinters had an average of 13.1 competitions for men and 11.4 competitions for women. When the same variable was analysed for the high jump, the authors stated that men had an average of 8.8 competitions and women had an average of 9.1 competitions (Örs ve Bayraktar, 2020). Moreover, Gandelsman and Smirnov as cited in Bompa, 2009 , suggested that an athlete should compete seven to ten competitions to reach peak performance. In this research, it was found that elite long jumpers had an average of 10.1 competitions for men and 9.2 competitions for women which supports the literature.

\section{Conclusion}

When the SB prediction model related to AF2P found in this study was applied to five male and five female long jumpers on the World lists in 2019, it was seen that the model predicted the SB performance with an average difference of $0.9 \%$ for male athletes and $1.4 \%$ for female athletes. Moreover when the SPA prediction models were applied to five male and five female long jumpers from the 2019 World lists; the models predicted the performance with a $0.66 \%$ and $\% 1.54$ percent differences for male and female long jumpers respectively. Since models can predict the actual SB performance with such a close percentage of difference; prediction models will enable trainers to predict the performance of their athletes in target competitions when the season starts and to do training/competition period accordingly. 